\title{
The Research on the Optimum Design Strategies of the Public Space Against the Background of Active Aging
}

\author{
Shidan $\mathrm{Wu}^{1, *}$
}

${ }^{1}$ Fuzhou University, Xiamen, Fujian 361000, China

"Corresponding author. Email: 184712020@qq.com

\begin{abstract}
The urban public space is an important part of the daily living space of the elderly. The paper explores the practical significance of the urban public space in meeting the psychological needs of the elderly and their will to participate in the society. The urban elderly space based on the concept of active aging, is conducive to the spiritual consolation and satisfaction of the elderly in the space with multigenerational integration, multi-functional combination and guidance and helps guide the elderly to realize their self-worth through learning and creating and participating in the society more comprehensively. Based on the theory of active aging, the paper analyzes the differences of the functions of the urban public space for the elderly in China and in view of the limitations of the design of urban public space for the elderly in China. With typical cases in China and abroad, it proposes the ideas and directions of optimum designs of urban public space for the elderly and summarizes the design strategies of the active responses to aging of the urban public space for the elderly.
\end{abstract}

\section{Keywords: active aging, public space, design strategies, learning and creation, participation in the society}

\section{INTRODUCTION}

The three-dimensional construction of urban public transportation system tends to weaken the traditional regional and time domain restrictions of urban public space, and the radius of daily life activities of the elderly group can be effectively extended from the neighborhood and community public space to the urban public activity space far away from the residence. Community public space and urban elderly public welfare activity space, as the most important activity places for the elderly, are not only the spiritual home to maintain communication and exchange between the elderly, but also the bridge for them to integrate into the society and participate in social activities. Against the current background of active aging, how to design public space to meet the needs of the elderly at different levels and help the elderly to improve their overall quality of life has become the focus of attention of many scholars in China and abroad, and has been studied in various aspects.

\section{RESEARCH ON PUBLIC SPACE DESIGN FOR THE ELDERLY IN CHINA AND ABROAD}

In Europe, America, Japan, Singapore and other countries and regions, the research and practice of public space design for the elderly have been carried out earlier, forming a relatively rich theoretical system and experience, which is constantly evolving and improving. In the early 1970s, Japan and Singapore conducted a research on barrier-free design of public space for the elderly, which is systematic, detailed and humanized in the design of urban public space, fully reflecting the society's care for the vulnerable groups [1]. These public space designs are mainly barrier-free designs to meet the elderly's living environment and physiological needs of public spaces such as parks and libraries [2]. The European and American countries represented by the United States, the United Kingdom and Australia are committed to developing the research and construction of large retirement communities and providing integrated facilities and services such as housing, health care and daily care for the elderly [3]. Retirement communities in Europe and the United States provide a large number of outdoor activities for the elderly to relax and entertain, and meet the physiological, psychological and social needs of the elderly through the combination of different spatial characteristics and high accessibility design [4].

After referring to relevant design research and practice abroad and combining with the current concept of "active aging", China's practitioners of public space for the elderly put forward the design strategy of public space for the elderly based on the idea of suitable aging design. For example, Ma Ying proposed the design proposal of multi-generation shared public service facilities in college housing areas [5]. Liang Weinan proposed to analyze the public space of distributed community suitable for aging transformation, so as to meet the physiological and social needs of the elderly 
[6]. Li Xinyang analyzed and summarized the needs and preferences of elderly groups for public space, and proposed several types of public space suitable for aging that should be configured around the community [7].

As mentioned above, Japan, Singapore and other countries focus on the design and research of barrierfree public space for the elderly in urban areas, while European and American countries focus more on the design and research of barrier-free public space for the elderly in large communities, realizing the implementation and transcendence of barrier-free design [8]. Due to the influence of geographical environment, population and other factors, there are few practices in large elderly communities in China, which mainly focus on the aging design research of the living environment and the surrounding communities, and also preliminarily explore the design ideas of fullage communities [3] [9]. Although some achievements have been made in the research and practice of these directions, there are few systematic studies on urban public activity space and institutional public space for exclusive elderly groups. In addition, most studies on public space design at home and abroad mainly focus on the "health" aspect of "active aging", and seldom involve the needs of social participation, respect and self-realization of the elderly. Therefore, this study starts with the urban public space and the institutional public space for the elderly group to analyze and study the design strategies of relevant public space. It aims to provide reference for the design of urban public space and construction, make the old public space effectively improve the social participation of the elderly, to guide the learning and creating of them, inheriting the rich knowledge and experience of old people, to achieve self-realization and social respect for the old.

\section{FUNCTIONS AND FORMS OF THE EXISTING PUBLIC SPACE FOR THE ELDERLY}

In this paper, public space refers to the main places of public activities for the elderly in the daily life. It is also an important part of urban public space at the same time, mainly including park, library and other large urban public welfare activity space, and special elderly activity center for the elderly, the elderly university sports, medical institutions, such as, nursing homes, not limited to housing surrounding space.

Active aging includes three major policies of health, participation and protection, among which "health" includes the meaning of "physiological, spiritual and social connections" [10] [11]. The proposal of active aging is also a new interpretation and sublimation of Maslow's hierarchy of needs theory in aging, which will be materialized into urban public space construction and design through the understanding and experience of urban builders. However, the social role and cultural psychological implication of "old" in the context of traditional Chinese culture make people's interpretation of the concept of "active aging" mostly stay at the level of physical health, ignoring the needs of mental health and social connection and participation of the elderly. In addition, although the concept of "home-based care, community service and institutional care" as the core and the pattern of "9073" and its derived pension model have initially constructed a multi-level social pension system in China [12], they have not provided more active and effective guidance in social participation, respect and self-realization of the elderly.

Therefore, from the three dimensions of "physiology, spirit and participation", this paper analyzes the guiding effect and effect of public space for the elderly on the health of the elderly, in order to reflect the similarities, differences and shortcomings of the public understanding of "active aging", and thus summarizes the corresponding space design strategies. Based on the analysis of the impact and effect of the public space for the elderly on the above three dimensions in terms of functions, service objects and characteristics, the comprehensive evaluation of the positive promotion and guidance effect of the public space for the elderly on the elderly group is obtained according to the rating from $1 \mathrm{~A}$ to $5 \mathrm{~A}$ for each dimension (the sum of the three items above $10 \mathrm{~A}$ indicates good) ("Table I") 
TABLE I. ANALYSIS OF THE EFFECT ON THE HEALTH OF THE ELDERLY IN URBAN SPACE

\begin{tabular}{|c|c|c|c|c|c|c|}
\hline \multirow{2}{*}{$\begin{array}{l}\text { Public space for } \\
\text { the elderly }\end{array}$} & \multirow{2}{*}{$\begin{array}{c}\text { Spatial service } \\
\text { object }\end{array}$} & \multirow{2}{*}{ Spatial characteristic } & \multicolumn{4}{|c|}{ Its active role in promoting and guiding the elderly } \\
\hline & & & Physiology & Spirit & Participation & $\begin{array}{c}\text { Comprehensive } \\
\text { evaluation }\end{array}$ \\
\hline $\begin{array}{c}\text { Institution of } \\
\text { medical treatment } \\
\text { and endowment }\end{array}$ & $\begin{array}{l}\text { Elderly people } \\
\text { with good basic } \\
\text { physical fitness } \\
\text { who need } \\
\text { regular care and } \\
\text { no children to } \\
\text { support }\end{array}$ & $\begin{array}{l}\text { With medical care, } \\
\text { medical care as the main } \\
\text { function space, the } \\
\text { configuration of } \\
\text { professional endowment } \\
\text { and other humanized } \\
\text { facilities }\end{array}$ & AAAAA & A & $\mathrm{A}$ & General \\
\hline Leisure park & $\begin{array}{l}\text { Multi-generational } \\
\text { groups }\end{array}$ & $\begin{array}{l}\text { The configeration of } \\
\text { fitness equipment and } \\
\text { other humanized } \\
\text { facilities focusing on } \\
\text { entertainment, leisure } \\
\text { outdoor space }\end{array}$ & AA & AAA & AA & General \\
\hline $\begin{array}{l}\text { Education Centre } \\
\text { for the elderly }\end{array}$ & $\begin{array}{l}\text { The elderly } \\
\text { population with } \\
\text { good basic } \\
\text { physical fitness }\end{array}$ & $\begin{array}{l}\text { Mainly the popularizing } \\
\text { health preservation, } \\
\text { literature and art courses } \\
\text { in the space design mode } \\
\text { of traditional row of } \\
\text { tables - platform }\end{array}$ & AAA & AA & AA & General \\
\hline $\begin{array}{l}\text { Senior citizens } \\
\text { activity center }\end{array}$ & $\begin{array}{l}\text { The elderly } \\
\text { population with } \\
\text { good basic } \\
\text { physical fitness }\end{array}$ & $\begin{array}{l}\text { Mainly the indoor space } \\
\text { for entertainment and } \\
\text { leisure configured with } \\
\text { fitness equipment and } \\
\text { other humanized } \\
\text { facilities }\end{array}$ & AA & A & A & Low \\
\hline Library & $\begin{array}{l}\text { Multi-generational } \\
\text { groups }\end{array}$ & $\begin{array}{l}\text { Mainly the interior space } \\
\text { is for study and leisure } \\
\text { configured with } \\
\text { universal facilities }\end{array}$ & A & $\begin{array}{l}\text { AAA } \\
\text { A }\end{array}$ & $\mathrm{A}$ & Low \\
\hline
\end{tabular}

In the above "Table I", in addition to the medical care space taking the medical treatment and care needs of the elderly as the main design orientation of the space, the existing public space for the elderly basically takes the concepts of leisure, recreation, recreation and health care as the design demand orientation of the space. The function and characteristics of space have little effect on the promotion and guidance of "social participation, respect and self-realization" of the elderly group. It reflects the main characteristics of the public space for the aged: the main function of the space design is relatively simple; the spatial properties are relatively monotonous; space is not very inclusive to multi-generational people, and does not play a prominent role in space communication among them.

\section{RESEARCH ON OPTIMAL DESIGN}

\section{STRATEGY OF SPACE FOR THE ELDERLY}

"As human is the service subject of space design, space design and construction should revolve around human activities, which includes not only human physical activities, but also human psychological activities. And people's physical activities are often dominated by psychological activities, so people's psychological feelings in space are also the core of space design [13]." Through the analysis of the existing old public space, it is found that the existing public space design for the elderly has many shortcomings and deficiencies in psychological healing, emotional belonging and social interaction of the elderly, and the high-level concepts of social connection and participation, respect and self-realization in active aging have not permeated into the initial positioning and later practice of space design. The current "9073" model means that $97 \%$ of the elderly's daily life is concentrated in the community home-based care space. The public space for the elderly, as an effective adjustment for the daily life of the elderly, is an important place to provide the spiritual pursuit and selfrealization of the elderly. Therefore, it is extremely 
important to summarize the optimization design strategy for the public space for the elderly.

\section{A. Space design that strengthens participation}

The elderly generally believe that the frequency of attending community activity centers, universities for the elderly and traveling are highly positively correlated with the quality of life [14]. At present, the public space design for the elderly is mostly realized by simple and one-sided methods such as adding barrier-free facilities or accessibility design into the original space design of buildings. The space design strategy to cope with the aging of the population actively should weaken the positioning of space "endowment" and focus on strengthening the social participation of the elderly on the premise of ensuring the full safety of the elderly. It should take creation and participation as the leading direction of design, establish a guiding space suitable for creation and re-education of the elderly, guide the elderly to participate in learning and educational activities, and stimulate the enthusiasm of the elderly to participate in social creation. This kind of space can be in the form of building group, which forms complementation and promotion between each space and can guide the elderly to go from a space of one attribute into one of another attribute; it can also be the vertical direction of the building for multi-functional streamline organization, which forms a diversified design thinking that focuses on creation, participation, medical care and fitness, realizing the transformation from the traditional passive endowment space of leisure and recuperation to the active endowment space of social participation and self-realization.

\section{B. Functional hybrid space design}

"The diversity and uncertainty of activity types and time will inevitably lead to the diversity of elderly people's demands for residential public activity places, so as to meet their demands for solitude, communication, public activities, child care and other activities [15]." At present, the functional attributes of the public space for the elderly are relatively single, which makes the behavior and activities of the elderly in the space relatively stable. For example, most nursing homes focus on medical care, most activity centers for the elderly focus on recreation, and universities for the elderly focus on re-education. The functions of each public space are independent of each other. In urban construction, different public spaces for the elderly are often far apart from each other, with independent functions and lack of connection and complementation, which cannot meet the multiple needs of the elderly at the same time. To solve this problem, the author puts forward the design strategy of the mixed functional space for the elderly. Based on the principle of unity of physical and mental health of the elderly, the design strategy, according to the different positioning of the main space of the elderly, combined with the willingness of the elderly to participate in activities, transitions and integrates various functional spaces to form a variety of mixed functional space design. In this paper, different attributes of the public space for the elderly are integrated according to different themes, and the following "Table II" is formed, which can be used as a reference for designers' practice in the early stage or later stage, in order to play a certain role in the construction of buildings for the elderly or the design of space for the elderly.

TABLE II. NEW TYPE OF SPACE IS MADE UP OF A MIXTURE OF DIFFERENT FUNCTIONS

\begin{tabular}{|c|c|c|}
\hline Theme & The content of the activities involved & Space type \\
\hline Leisure and educational shopping themes & $\begin{array}{l}\text { Service-oriented consumption, continuing } \\
\text { education, making friends }\end{array}$ & $\begin{array}{l}\text { Commercial space }+ \text { re-education } \\
\text { space }\end{array}$ \\
\hline Entertainment, fitness and education theme & $\begin{array}{l}\text { Entertainment, fitness, experience sharing, } \\
\text { making friends }\end{array}$ & Recreation park + education base \\
\hline The theme of recuperation and self-realization & Treatment, healing, creative act & Maker space + medical care space \\
\hline Innovation and creation themes & $\begin{array}{l}\text { Continuous learning, creation behavior, making } \\
\text { friends }\end{array}$ & $\begin{array}{l}\text { Re-education space }+ \text { independent } \\
\text { creation }\end{array}$ \\
\hline $\begin{array}{c}\text { Exercising, making friends and creating themes } \\
\text { independently }\end{array}$ & $\begin{array}{l}\text { Entertainment, fitness, making friends, creating } \\
\text { behavior }\end{array}$ & $\begin{array}{l}\text { Senior park }+ \text { independent maker } \\
\text { space }\end{array}$ \\
\hline
\end{tabular}

1) Integrating the theme space of leisure and education: For the elderly, the commercial atmosphere of comprehensive commercial places is too strong, and there are few products and services suitable for the elderly; yet most of the re-education places for the elderly belong to public welfare nature, which only imparts the knowledge and experience of health and leisure for the elderly, and lacks some service-oriented consumption places. The commercial service space for the elderly should be properly integrated into the re- education space, so that the elderly can enjoy some consumption services in the process of learning and reeducation, and improve their communication quality. The integration of re-education space and comprehensive commercial space for the elderly can not only ensure the basic physiological needs of the elderly, but also meet the improvement of knowledge and skills, which is also a new idea for the design of comprehensive service building for the elderly. 
2) Theme space that integrates entertainment, fitness and education: Only when the elderly continue to exert their strength in the society can they truly feel the value of their existence [16]. Some elderly people have rich experience, profound knowledge and valuable practical experience, which is a rare spiritual wealth for the society. In order to better continue and inherit this spiritual wealth, the design of the elderly park can be combined with the education base to build a platform and space for the elderly to share their experience. Such a platform can combine the intergenerational education model, integrate the common and shared public space between the elderly and the young, promote the full interaction between the elderly and groups at different age levels, and realize the transfer and transmission of knowledge, experience, skills and resources of the elderly.

3) Theme space blending medical treatment and endowment and creation: Some older persons need to live in elderly care institutions due to physical health problems, which, although conducive to the recovery of physical health, often makes them more mentally isolated due to lack of communication and social participation. The integration of maker space into the traditional centralized medical maintenance space can guide the elderly to spontaneously participate in some of the manual creation or artistic creation in the intervals of medical treatments and maintenance. It will be conducive to activating the thinking of the elderly, rejuvenating their mental outlook, and enrich the life of the convalescing group and make them participate in the creation of society to the best of their ability, which is of great benefit to the maintenance of the physical and mental health of the elderly.

4) Theme space of innovation and creation: Since the 21 st century, the degree of global informatization has accelerated, and innovation and creation in various industries have emerged in endlessly. At present, most of the re-education institutions for the elderly in China basically take leisure culture, health care and health as the theme, which has a certain gap with the theme of "creation by all and innovation by all" currently advocated in China. The professional knowledge and experience of many elderly people gradually fall into disuse after retirement, which is a loss and waste of resources for both the society and the family. Therefore, attempts can be made to introduce a new education mode in the re-education space for the elderly, and let some geriatricians and workers with rich professional knowledge and experience to teach or exchange experience, supplemented by targeted industrial space for the elderly to make innovations and creations. This combination of learning and creation, which integrates the re-education space with the creative space of the elderly, is conducive to the continuation and inheritance of knowledge and experience of the elderly, and guides the elderly to actively participate in social creation, giving full play to the linkage effect of learning, communication and creation, and makes contributions to social benefits.

According to the different positioning of the design subject, combining different themes, a variety of theme space can be formed, which is not discussed here. These theme spaces can be realized through a different combination of architectural layouts or spatial forms. To be specific, on the premise of sufficient land, open integration of different functions of different building groups can be carried out in the construction planning of new urban areas. However, some old urban areas can be transformed and optimized according to the specific situation through vertical layered functional differentiation or embedded layout, so as to achieve full interaction and connection between different areas and functions. For example, the welfare complex building located in the central area of Rotterdam (Het Oude Noorden) is a comprehensive elderly building integrating shopping, leisure and life services, commercial services and medical care [17]. In this building, vertical stratification design is carried out in the functional space. The spatial functional layout and usage mode are different from the traditional sanatorium, and different floors are equipped with differentiated functions. The frequent interaction between floors makes the activities of the elderly in the space more clear and rich. From the perspective of human nature, these designs solve the disorder of the elderly's life after retirement, which is conducive to improving the positive mental state of the elderly. This way of theme space design makes modern public space design more attractive and modern, which should be part of the topic of public space design [18].

\section{Space design allowing multi-generational interaction}

The "generation" in "multi-generational" refers to an identifiable group of individuals who share a common birth year, age stage, and major life events that go through a critical growth stage. Multi-generation refers to the communication between people of different ages and different experiences.

After retirement, the elderly tend to feel lonely and neglected by the society, hoping to reintegrate into the society in another way. However, due to the simplicity of its spatial function, the traditional centralized endowment space has limited users, reducing the contact between the elderly and other social groups, and failing to meet the needs of spiritual communication. The design of multi-generational space can well meet the needs of the elderly to re-participate in and integrate 
into the society. This kind of space design meets the space needs of different groups, is highly inclusive, and has the spatial characteristics of integrating into the social multi-groups and serving multi-objects, making the physical, psychological and social needs of different groups highly fit in space.

Japan's Nozoe Day Care Center for the elderly is a typical case of multi-generational public space design integrating multifunctional facilities such as those for children and elderly groups (see "Fig. 1") [19]. In this project, the public intersection space - atrium courtyard and dining area - is set between the two main buildings of the day care center for the elderly and the kindergarten. The outdoor courtyard interaction and dining are arranged regularly every day, realizing the full contact and interaction between the elderly and children in the shared space and promoting the emotional communication between the elderly and children. This design of public space not only enables the elderly to receive different care experience, but also enables the young children to have a more detailed understanding of the world of the elderly through their contact with the elderly and get close contact with their extraordinary life, thus realizing the spiritual win-win of two generations [20]. Taking the Intergenerational Service Center around Xidian University as another example (see "Fig. 2") [5], the designer made a new design breakthrough in the different nature of the layout of the building, with the elderly complex, youth apartments, affiliated primary and secondary school planned in adjacent, and there is a public playground in the south at the same time. This kind of space design and planning greatly improves the crossover density between the elderly group and other groups, and at the same time meets the needs of the interactive function of multi-generation space for shared activity. Thus it can be seen that the advantages of multi-generation space are embodied in that the elderly can keep their dominant activity space to the maximum extent while taking into account the activity space of other groups.

The design strategy of multi-generation space is to pay attention to the social participation of elderly individuals and the diversity of activity space population, expand the social scope of the elderly and other social groups, so as to design a friendly space that conforms to the close interaction between the elderly and different groups. In addition, since older people mostly prefer slower pace of life and enjoy peace, efforts should be made to keep the elderly's dominant position in the process of interaction with other social groups. The participation proportion of children, adolescents and adults should thus be appropriately limited to avoid the excessive occupation of space by other groups, which may lead to the change from a dominant position to a subordinate position of the elderly.

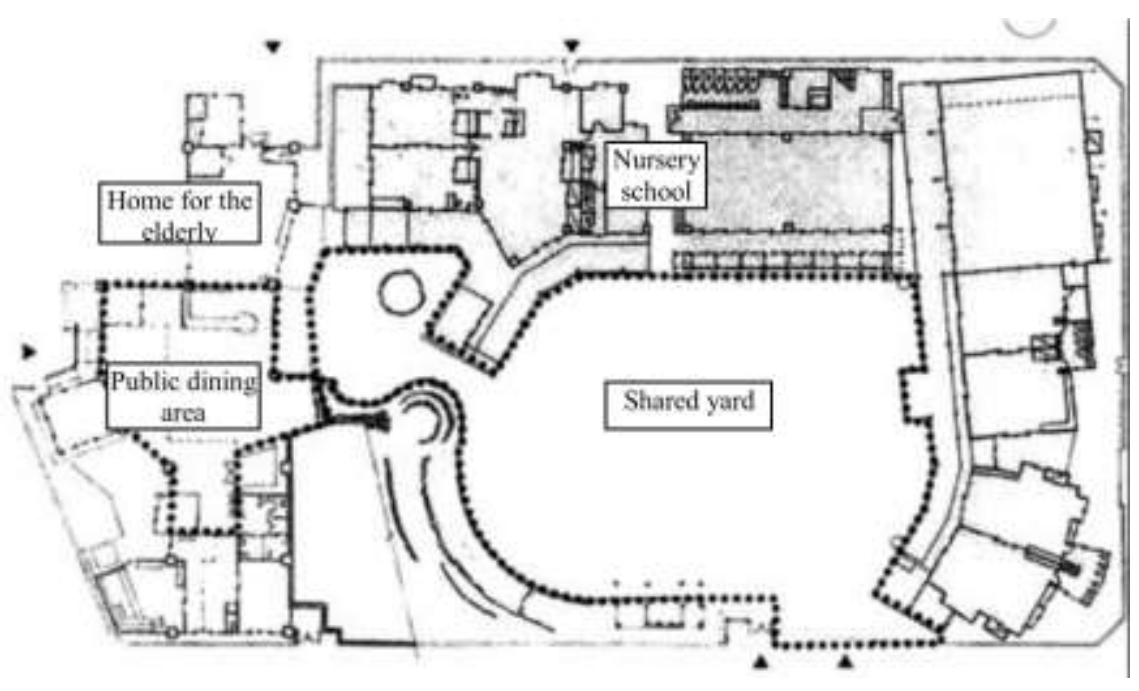

Fig. 1. Day Care Center for the elderly in Japan.. 


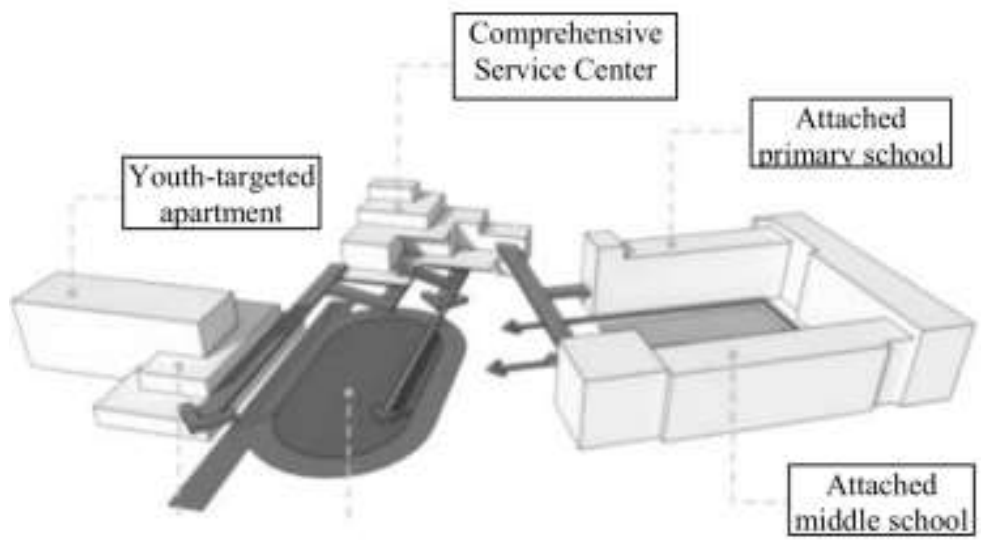

Fig. 2. The Architecture of Comprehensive Service Center for the Elderly and surrounding buildings in Xi'an University of Science and Technology.

\section{CONClUSION}

The gradual implementation of the strategy and policy of "active response to aging" in China will inevitably arouse the public's great attention to the health, participation and protection of the elderly. Urban public space for the elderly will become an important part of urban public space, and its space design will change from the existing design suitable for aging transformation and accessibility to the integrated design that integrates the needs of each important stage of human life process. "Design leads the city" is not only a slogan, but should guide the elderly to participate in social activities with healthy physical functions and a more energetic state of mind through the materialization of design. There might be some shortcomings in optimal design strategy of public space proposed by the author for the elderly, though. Yet it is no denying that the public space for the elderly has a positive role in guiding the health of the elderly and contributes to the overall quality of life of the elderly. Therefore, it is expected that this paper can provide some reference and inspiration for urban space designers and practitioners.

\section{References}

[1] Deng Ling-yun, Zhang Nan. Analysis on the construction of barrier-free design system for urban public space in Japan [J]. Urban Planning International, 2015 (30): 106-110.

[2] Zhang Xiao, Li Chao-yang, Miao Jun-qiang. Reflections on humanization and Universal Design of Urban living Space: barrier-free Design of Urban living Space in Singapore and its Enlightenment [J]. Modern Urban Research, 2014 (12): 19-24.

[3] Li Xiaoyun. The development of retired community in foreign countries and its enlightenment to the construction of elderly community in China [J]. Urban Study, 2018, 25 (5): 81-88.

[4] Yin Jie, Peng Zhong-ren.Active Ageing: Inspiration of the Active Adult Retirement Community in the United States [J]. International urban planning, 2017, 32(6): 125-131.
[5] Ma Ying. Research on Multi-generational sharing Strategy of Public Service facilities in Residential District of Colleges and Universities under the goal of assisting the elderly [D]. Xi'an: Xi'an University of Architectural Science and Technology, 2015.

[6] Liang Wei-nan, Cao Yang. Research on Public Space Design based on Community Endowment Model [J]. Urban Study, 2012, 19 (11): 8-10.

[7] Li Xinyang, Hong Zaisheng, Yuan Yiqing, Zhao Lizhi, Xu Minjie. Research on Public Space of City Elderly, Children Research on suitable Community Public Space [J]. Urban Study, 2015, 22(5): 104-111.

[8] [8]Kirsten J C. CRS Report for the Congress: Supportive Services Programs To Naturally Occurring Retirement Communities [M].Washington, DC: Congressional Research Service, 2007.

[9] Wu Xiuqi. Research on the Reconstruction of Age Community Planning in China under the background of active Aging [J]. Modern City Research, 2018 (08): 2-6.

[10] World Health Organization. Active Ageing: A Policy Framework[R/OL]

http://www.who.int/ageing/publications/active_ageing/en/. 2002.

[11] Liu Wen,Jiao pei.A study on active Aging in International Perspective $[\mathrm{J}]$. Journal of Zhongshan University (Social Sciences Edition), 2015: 55 (1): 167-180.

[12] Nie Riming. Shanghai "9073" pension model [J]. Advance in the Same Boat, 2018 (4): 8-11.

[13] Yan Sida. Feeling and construction of public space [J]. Art Work, 2018 (6): 102.

[14] Liang Xun, Kong Xiuli, Chen Ning, Li Wanqiang. A study on the quality of life of healthy elderly based on the design of community pension service [J]. Packaging Engineering, 2015, 36 (12): 10-15

[15] Jin Yuan.Research on the resettlement of public space in the context of adaptability: Taking Longhu Park in Huainan City as an example [J]. Chinese and Foreign Architecture, 2020(2): 103.

[16] Han Dong-nan, Bian Kun. Application Design for the Elderly Network Community in Aging Society [J]. Packaging Engineering, 2013, 34(22): 119-122.

[17] Arian Mosteadi. Housing for the elderly: housing Strategy in the Silver Age [M]. Yang Xiao-dong, Zhong Sheng translated into Beijing: machinery Industry Press.2008.

[18] Huang Zhixin. Research on the Integration of traditional decorative elements in modern public space design [J]. Art Work, 2018(3): 85 
[19] Yuan Yi-xin, Liu Chao and Li Wei. The study on the design pattern of community-based elderly daily-care center and community-based kindergarten [J]. Urban space design, 2014 (2): $142-145$.

[20] Xu Xiao-juan, Wang Xu-lin, Li Lin et al. Research on Intergenerational Learning abroad: theoretical basis, Cooperative sharing Space and 3P practice [J]. Journal of Distance Education, 2018(3): 105-112. 